\title{
RANCANG BANGUN SISTEM KENDALI ALAT PENYORTIR BARANG BERWARNA MERAH DAN HIJAU DENGAN SENSOR TCS230 BERBASIS PLC SCHNEIDER
}

\author{
Agri Denada Br Tarigan, Iman Setiono \\ Program Studi DIII Teknik Elektro Departemen Teknologi Industri \\ Sekolah Vokasi Universitas Diponegoro Semarang \\ Jalan Prof. Sudharto, SH Tembalang Semarang \\ e-mail : Agridenada5@gmail.com
}

\begin{abstract}
Agri Denada Br Tarigan, Iman Setiono, in this paper explain that temperature regulation is one of the most important needs for the industry. Lots of processes and production are carried out under certain temperature conditions and free from interference. Industrial temperature controller is one of the basic equipment to meet these needs. On the market there are various types, specifications, and brands of temperature controllers, but have similarities with one another mainly lies in the basic functions of temperature regulation capabilities. This article describes the background of industrial temperature controllers principal, also covers control concepts, basic controller configurations, control methods, actuator equipment support, and examples of sensor parameter settings and controls on the Autonics TC4S series temperature controllers.
\end{abstract}

Keywords: Temperature regulation, industrial temperature controller, ON-OFF control, PID

\section{Pendahuluan}

Kemajuan teknologi pada zaman sekarang ini sudah semakin berkembang dan sangat memungkinkan manusia untuk membuat alat yang dapat membantu mempermudah pekerjaan yang di buat. Sistem kendali adalah suatu kumpulan alat yang berfungsi untuk mengendalikan, memerintah, dan mengatur keadaan suatu sistem. Sistem kendali juga merupakan hal yang paling utama dilakukan pada alat sehingga dapat dikendalikan sesuai pembuatanya. Sistem kendali yang sudah ada sekarang ini ada berbagai macam seperti Arduino, PLC, Mikrokontroler dan lainnya. Ini menunjukkan bahwa sistem kendali alat sangat penting dalam membantu melakukan suatu proses produksi disetiap perusahaan industri.

PLC merupakan salah satu bidang pengontrolan yang mengambil peranan penting dalam menjalankan berlangsungnya proses produksi di perusahaan industri. Banyak keuntungan yang terdapat pada penerapannya di dunia industri, diantaranya dalam pengawasan proses dapat dilakukan dari jarak jauh, mengintegrasikan sistem yang berjauhan, mengurangi kesalahan- kesalahan yang disebabkan oleh Human Eror, dan dapat melakukan perekaman proses. PLC juga merupakan suatu alat kontrol yang dilengkapi dengan software untuk membuat sistem kontrol sesuai keinginan kita. PLC memiliki kelebihan berbeda dengan sistem kontrol lainnya adalah PLC lebih Fleksibelitas,dapat menyerdehanakan Komponen-komponen sistem kontrol dan juga memiliki kecepatan operasi untuk mengaktifkan fungsi-fungsi logika dalam waktu yang relatif cepat dibandingkan dengan mikrokontroller yang lain.
Dalam alat penyortir barang berdasarkan warna ini penyusun menggunakan pengendali berupa PLC. Dimana sistem kontrol berbasis PLC ini diberikan tambahan rangkaian Logic Converter pada bagian input yang digunakan untuk mengubah logika masukan sensor TCS230 yang berupa sinyal frekuensi yang diubah menjadi bentuk logika sebelum dihubungkan pada input-an PLC. Pada PLC penyusun juga menambahkan rangkaian digital Input dan digital Output untuk menjalankan fungsi kerja PLC dalam kondisi high dan low sehingga lebih mempermudah dalam pengontrolannya.

Dengan perancangan alat ini diharapkan mempermudah proses penyortiran barang berdasarkan warna sehingga terciptanya suatu alat yang praktis dan cepat dalam pemisahan barang. PLC ini digunakan karena lebih fleksibilitas, dapat menyederhanakan komponen-komponen sistem kontrol dan juga memiliki kecepatan operasi untuk mengaktifkan fungsi-fungsi logika dalam waktu yang relatif cepat dibandingkan dengan mikrokontroller yang lain.

\section{Sensor TCS230}

Sensor warna TCS230 adalah sensor warna yang digunakan untuk pendeteksi warna pada suatu objek benda atau warna dari objek. Sensor warna TCS230 juga dapat digunakan sebagai sensor gerak, dimana sensor mendeteksi gerakan suatu objek berdasarkan perubahan warna yang diterima oleh sensor. Pada dasarnya sensor warna TCS230 merupakan konverter yang diprogram untuk mengubah warna menjadi frekuensi yang tersusun atas konfigurasi silicon photodiode dan konverter arus ke frekuensi dalam IC CMOS monolithic yang tunggal. Keluaran dari sensor ini adalah gelombang 
kotak (duty cycle 50\%) frekuensi yang berbanding lurus dengan intensitas cahaya (irradiance). Keluaran frekuensi skala penuh dapat diskalakan oleh satu dari tiga nilai-nilai yang ditetapkan via dua kontrol pin input.

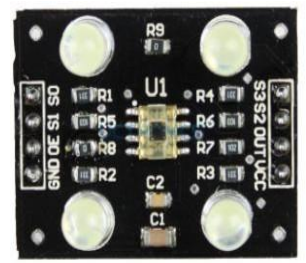

Gambar 1. Bentuk Fisik Sensor Warna TCS230

\section{Motor DC}

Motor DC merupakan suatu perangkat yang mengubah energi listrik menjadi energi kinetik atau gerakan. Motor DC memerlukan supply tegangan yang searah pada kumparan medan untuk diubah menjadi energi mekanik. Bagian utama motor DC adalah stator dan rotor dimana kumparan medan pada motor dc disebut stator (bagian yang tidak berputar) dan kumparan jangkar disebut rotor ( bagian yang berputar).

Prinsip dari arus searah adalah membalik phasa negatif dari gelombang sinusoidal menjadi gelombang yang mempunyai nilai positif dengan menggunakan komutator, dengan demikian arus yang berbalik arah dengan kumparan jangkar yang berputar dalam medan magnet dihasilkan tegangan (GGL).

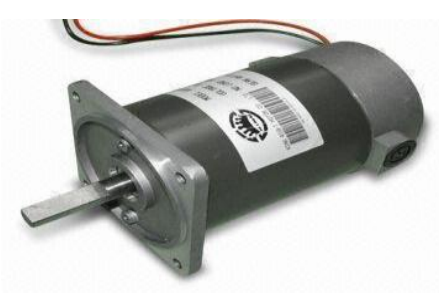

Gambar 2. Motor DC

\section{Motor Servo}

Motor Servo adalah suatu perangkat putar (actuator) yang dirangkai dengan kontrol umpan balik atau loop tertutup sehingga perangkat tersebut dapat disetting (atur) untuk memastikan dan menentukan posisi dari sudar poros output motor. Pada motor servo posisi putaran sumbu dari motor akan diinformasikan kembali ke rangkaian kontrol yang ada di dalam.

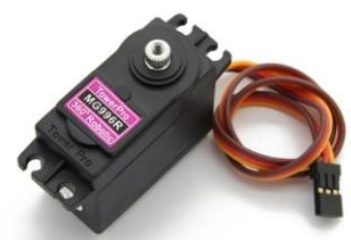

Gambar 3.Motor Servo

\section{PLC Schneider}

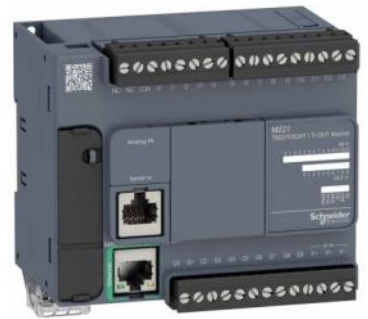

Gambar 4. PLC Schneider

PLC didefenisikan sebagai suatu perangkat elektronik digital dengan memori yang dapat diprogram untuk menyimpan intruksi-intruksi yang menjalankan fungsi-fungsi spesifik. Dalam mengeksekusi program, PLC memerlukan waktu scan untuk satu siklus eksekusi. Waktu scan ini terdiri dari beberapa proses ,yakni pemrosesan internal, pembacaan masukan, pemrosesan program dan pengeluaran keluaran. Pemrosesan ini menyangkutp enyalaan status lampu indikator, pendeteksian mode RUN atau STOP, dan lainnya. Proses pembacaan masukan merupakan proses membaca modul input yang digunakan. Pemrosesan program merupakan proses PLC dalam mengolah data input sesuai dengan program yang dibuat. Proses pengeluaran keluaran adalah proses PLC dalam mengeluarkan data yang akan dikeluarkan yang ditambahkan pada PLC. Semua proses ini dilakukan berurutan dan akan selalu berulang.

Relay

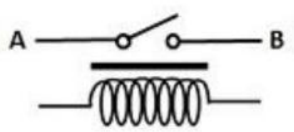

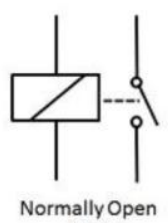

Normally Ope

Gambar 5.Relay

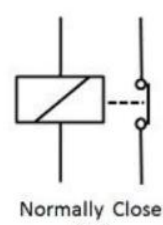

(NC)
Relay adalah suatu komponen elektronika yang menggunakan gaya elektromagnetik untuk memutus atau menghubungkan aliran besaran listrik. Relay terdiri dari 3 bagian utama, yaitu:

1. Common, merupakan bagian yang tersambung dengan Normally Close (dalam keadaan normal).

2. Koil (kumparan), merupakan komponen utama relay yang digunakan untuk menciptakan medan magnet.

3. Kontak, merupakan sejenis saklar yang pergerakannya tegantung dari ada atau tidaknya arus listrik pada coil. Ada 2 jenis kontak pada relay yaitu : norrmaly open dan norrmally close. 


\section{Arduino Atmega2560}

Arduino Mega2560 adalah papan pengembangan mikrokontroller yang berbasis Arduino dengan menggunakan chip ATmega2560. Board ini memiliki pin I/O (Input/Output) yang cukup banyak, sejumlah 54 buah digital I/O pin, 15 pin diantaranya adalah PWM (Pulse Width Modulation), 16 pin analog input, 4 pin UART (Universal Asynchronous Receiver Transmitter) serial port hardware. Arduino Mega 2560 dilengkapi dengan sebuah oscillator $16 \mathrm{Mhz}$, sebuah port USB (Universal Serial Bus), power jack DC (Direct Current), ICSP (In circuit serial programming) header, dan tombol reset. Board ini sudah sangat lengkap, sudah memiliki segala sesuatu yang dibutuhkan untuk sebuah mikrokontroler. Dengan penggunaan yang cukup sederhana, tinggal menghubungkan power dari USB ke PC atau melalui adaptor AC/DC ke jack DC.

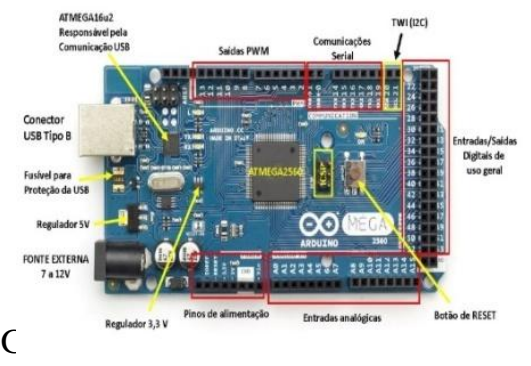

\section{Blok Diagram Rangkaian}

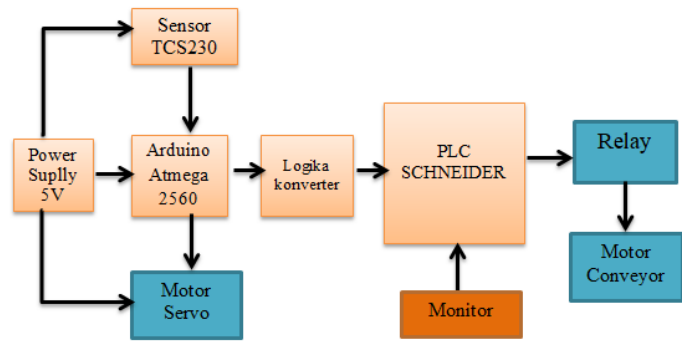

Gambar 7.Blok Diagram Alat

\section{Diagram alir Kerja Alat}

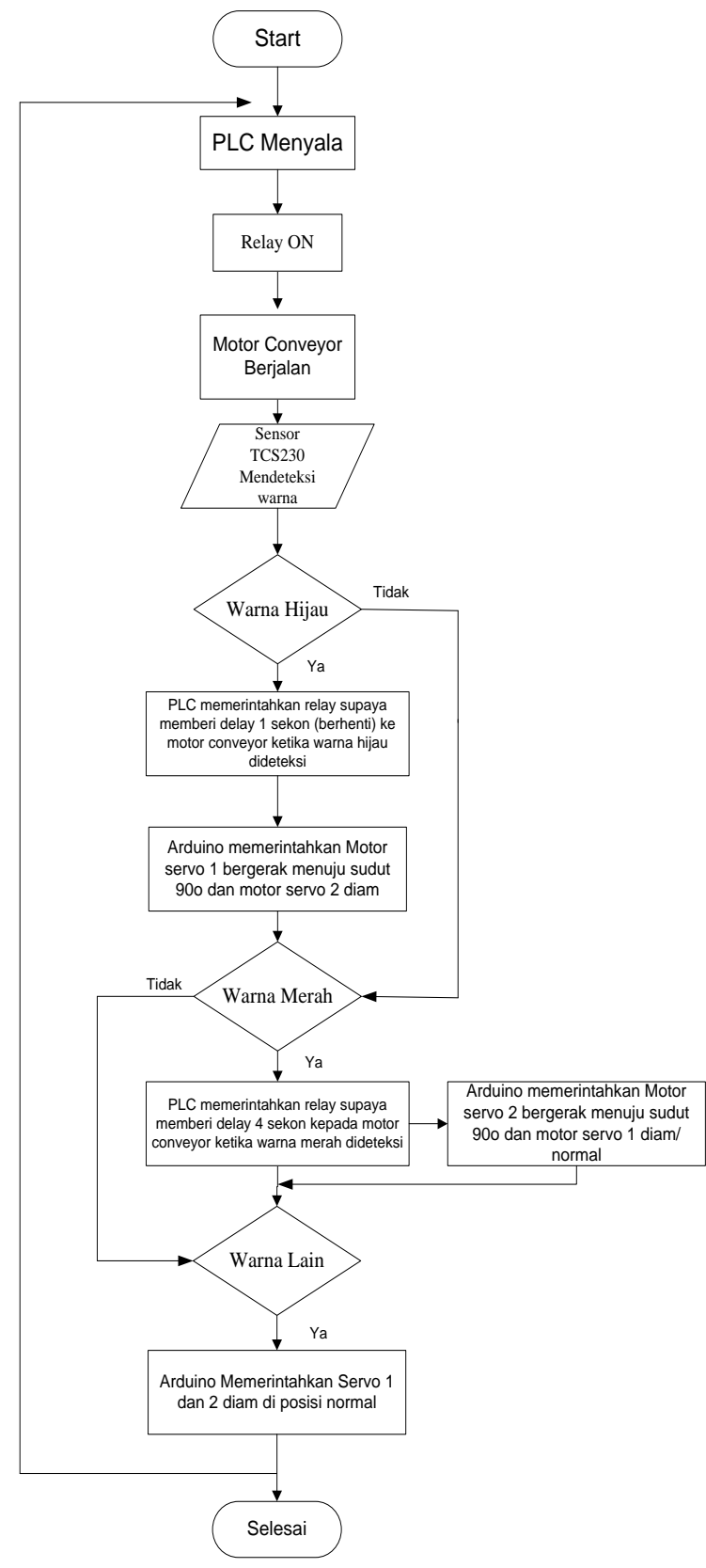

Gambar 8.Diagram alir Alat

\section{Rangkaian Catu Daya}

Rangkaian Catu Daya berfungsi untuk mengubah tegangan AC menjadi DC yang digunakan sebagai supply atau sumber daya untuk peralatan lain. 


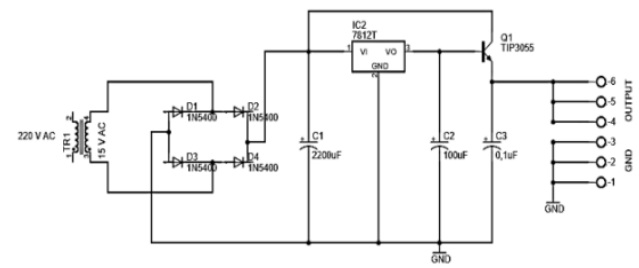

Gambar 9. Rangkaian Catudaya

\section{Rangkaian Logika Konverter}

Rangkaian Logika Konverter pada alat rancang bangun sistem kendali alat penyortir barang berwarna ini berfungsi untuk mengubah logika inputan dari sensor TCS230 yang berupa frekuensi diubah kedalam bentuk level tegangan TTL berupa logika high dan low. Logika converter ini juga berfungsi untuk mengubah tegangan 5 VDC menjadi 24 VDC.

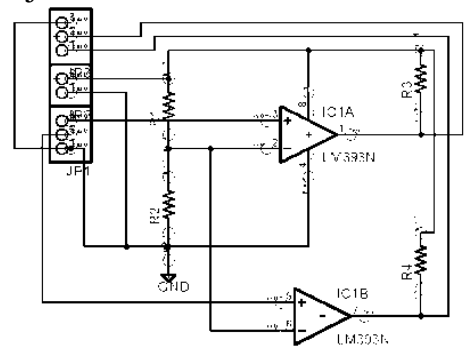

Gambar 10. Rangkaian Logic Converter

\section{Rangkaian Sensor TCS230}

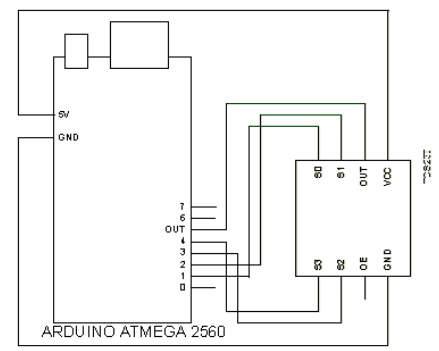

Gambar 11.Rangkaian Sensor TCS230

Rangkaian sensor TCS230 digunakan sebagai pendeteksi warna barang yang akan disortir.Rangkaian sensor warnayang dipakai di alat ini sudah berupa modul.

\section{Rangkaian Motor Servo}

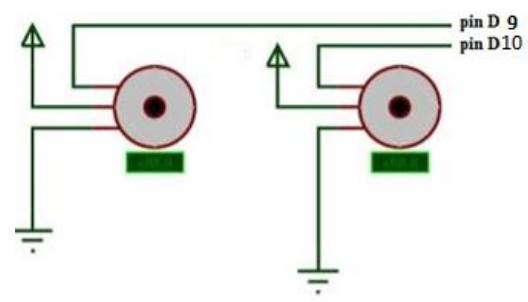

Gambar 12. Rangkaian Motor Servo
Rangkaian motor servo di alat ini berfungsi sebagai pendorong/tuas barang. Ketika barang sudah terdeteksi oleh sensor TCS230 maka motor servo akan mendorong barang masuk kedalam box sesuai warna yang dideteksi.

\section{Rangkaian Motor DC}

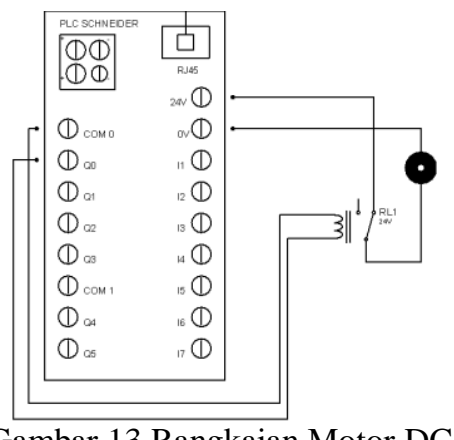

Gambar 13.Rangkaian Motor DC

Rangkaian motor DC pada alat ini berfungsi sebagai motor conveyor untuk menjalankan belt conveyor. Motor DC yang digunakan pada alat ini adalah Motor DC 24 Volt.

\section{Rangkaian Relay}

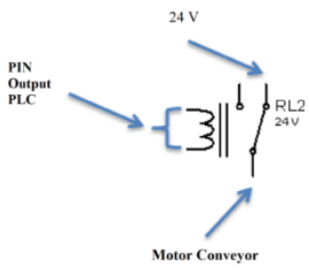

Gambar 13.Rangkaian relay

Rangkaian relay digunakan untuk memberi delay kepada motor DC. Relay 24 VDC ini mendapat tegangan sumber dari PLC. Relay pada alat ini berfungsi untuk memberi delay kepada motor conveyor ketika sensor TCS230 mendeteksi warna pada barang.

\section{Rangkaian PLC}

Rangkaian PLC digunakan sebagai pengendali atau otak untuk sistem kontrol alat penyortir barang serta penyimpanan programprogram perintah yang nantinya akan dihubungkan oleh rangkaian modul-modul tambahan agar bekerja sesuai yang penyusun inginkan. 


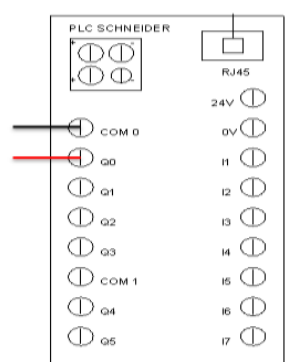

Gambar 14.Rangkaian Modul PLC Schneider

\section{Rangkaian Arduino}

Rangkaian Arduino Mega 2560 terhubung dengan sensor TCS230 dan motor servo di analog. Arduino mega juga terhubung dengan rangkaian logic converter di digital untuk mengubah tegangan dari 5 VDC menjadi 24 VDC.

\section{PENGUKURAN DAN PENGUJIAN \\ PengukuranRangkaian}

Pengukurandanpengujiandilakukanpadamasing -masingrangkaian. Hal itubertujuanuntukmendeteksikemungkinanadanyake salahanpadarangkaian.

Selainitujugauntukmengetahuinilaibesaranlistrikkel uarannya.

\section{Pengukuran Rangkaian Relay}

Tabel 1.Pengukuran Rangkaian Relay

\begin{tabular}{cccc}
\hline \multirow{2}{*}{ Nama } & Port & \multicolumn{2}{c}{ Tegangan } \\
Rangkaian & PLC & High & Low \\
\hline \multirow{2}{*}{ Relay } & Q1 & 24,23 & 0 \\
& & VDC & VDC \\
\hline
\end{tabular}

Relay di atasterhubungdengan motor konveyordantrigger relay terhubungpada port Q1 PLC sebagaipemberisinyal highataulow.

\section{Pengukuran Logika Konverter}

Pengukuran pada rangkaian Logika Konverter ini meliputi pengukuran outputan tegangan yang dihasilkan oleh Comparator, Tegangan inputan dari Mikrokontroler Arduino Mega2560 dan Tegangan Referensi . Rangkaian logika converter sebelum masuk ke Input dari rangkaian PLC. Dimana pengukuran ini untuk membuktikan bahwa perubahan level tegangan 5VDC Arduino ke 24 VDC PLC, sehingga memungkinkan pembacaan informasi yang diberikan Arduino berupa informasi pembacaan warna dari sensor TCS230 bisa diterima oleh PLC.
Tabel 2.Pengukuran Logika Konverter

\begin{tabular}{|c|c|c|c|}
\hline \multirow[b]{2}{*}{ No } & \multirow[b]{2}{*}{ Titik Yang Diukur } & \multicolumn{2}{|c|}{ Tegangan (VDC) } \\
\hline & & $\begin{array}{l}\text { High } \\
\text { (1) }\end{array}$ & $\operatorname{Low}(0)$ \\
\hline 1 & $\begin{array}{l}\text { TeganganReferensi } \\
\left(\mathrm{V}_{\text {ref }}\right)\end{array}$ & 2,262 & 0 \\
\hline 2 & $\mathrm{~V}_{\text {0ut }}$ Comparator & 24.23 & 0 \\
\hline 3 & $\mathrm{~V}_{\text {in }}$ Arduino & 5,02 & 0 \\
\hline
\end{tabular}

\section{Pengukuran Rangkaian Motor Conveyor}

Pengukuran rangkaian motor conveyor meliputi tegangan output yang dihasilkan oleh PLC Dalam pengukuran rangkaian motor Konveyor ini juga terdapat 2 kondisi logika, yaitu kondisi logika high dan logika low.

Tabel 3.Pengukuran Motor Conveyor

\begin{tabular}{cccc}
\hline & Bagian & \multicolumn{2}{c}{ Tegangan $($ VDC) } \\
\cline { 3 - 4 } Titik & $\begin{array}{c}\text { yang } \\
\text { Diukur }\end{array}$ & $\begin{array}{c}\text { Motor } \\
\text { Bergerak }\end{array}$ & $\begin{array}{c}\text { Motor } \\
\text { Bergerak }\end{array}$ \\
\hline \multirow{2}{*}{1} & $\begin{array}{c}\text { Motor } \\
\text { Konveyor }\end{array}$ & 24,23 & 0 \\
\hline
\end{tabular}

\section{Pengukuran rangkaian Motor Servo}

Pengukuran rangkaian motor servo meliputi tegangan output yang dihasilkan oleh Arduino. Dalam pengukuran rangkaian motor servo ini juga terdapat 2 kondisi logika, yaitu kondisi logika high dan logika low sesuai dengan sinyal yang di berikan Arduino saat membaca warna yang terbaca oleh Sensor TCS230.

Tabel 4. Pengukuran motor servo

\begin{tabular}{ccccc}
\hline & Bagian & \multicolumn{3}{c}{ Tegangan (VDC) } \\
\cline { 3 - 5 } No & $\begin{array}{c}\text { yang } \\
\text { Diukur }\end{array}$ & $\begin{array}{c}\text { Motor } \\
\text { Mendo } \\
\text { rong }\end{array}$ & $\begin{array}{c}\text { Motor } \\
\text { Masuk }\end{array}$ & $\begin{array}{c}\text { Motor } \\
\text { Berhen } \\
\text { ti }\end{array}$ \\
\hline & & & & \\
1 & Servo 1 & 5,2 & 5,2 & 0,1 \\
2 & Servo 2 & 5,2 & 5,2 & 0,1 \\
\hline
\end{tabular}


Tabel 5. Lebar PWM Motor Servo

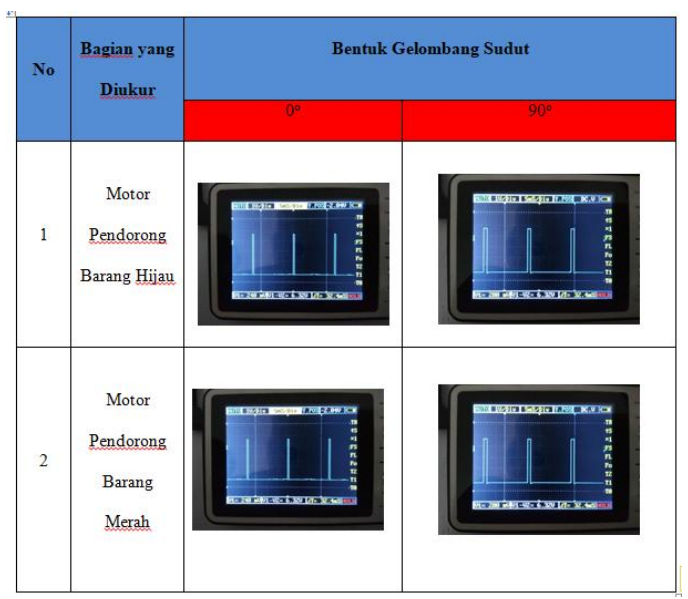

\section{Pengujian Hasil Uji sistem}

Percobaan yang dilakukan berupa pendeteksian barang berwarna merah dan hijau yang melewati sensor TCS230 yang menyebabkan motor pendorong

Tabel 6. Hasil Pengujian Alat

\begin{tabular}{|c|c|c|c|}
\hline No & $\begin{array}{l}\text { Deteksi } \\
\text { Barang }\end{array}$ & Hasil & Keterangan \\
\hline 1 & $\begin{array}{l}\text { Barang } \\
\text { Warna } \\
\text { Hijau }\end{array}$ & Error & $\begin{array}{l}\text { Motor conveyor } \\
\text { terlalu cepat } 1 \\
\text { sekon }\end{array}$ \\
\hline 2 & $\begin{array}{l}\text { Barang } \\
\text { Warna } \\
\text { Hijau }\end{array}$ & Berhasil & $\begin{array}{l}\text { Motor servo tepat } \\
\text { mendorong Barang } \\
\text { setelah melewati } \\
\text { sensor ( delay } 2 \\
\text { sekon ) }\end{array}$ \\
\hline 3 & $\begin{array}{l}\text { Barang } \\
\text { Warna } \\
\text { Hijau }\end{array}$ & Berhasil & $\begin{array}{l}\text { Motor sevo tepat } \\
\text { mendorong Barang } \\
\text { setelah melewati } \\
\text { sensor ( delay } 1 \\
\text { sekon ) }\end{array}$ \\
\hline 4 & $\begin{array}{l}\text { Barang } \\
\text { Warna } \\
\text { Merah }\end{array}$ & Error & $\begin{array}{l}\text { Motor Servo } 2 \text { tidak } \\
\text { merespon ketika } \\
\text { barang dideteksi } \\
\text { oleh sensor }\end{array}$ \\
\hline 5 & $\begin{array}{l}\text { Barang } \\
\text { Warna } \\
\text { Merah }\end{array}$ & Error & $\begin{array}{l}\text { Motor Servo } 2 \text { tidak } \\
\text { merespon ketika } \\
\text { barang dideteksi } \\
\text { oleh sensor }\end{array}$ \\
\hline 6 & $\begin{array}{l}\text { Barang } \\
\text { Warna } \\
\text { Merah }\end{array}$ & Berhasil & $\begin{array}{l}\text { Motor servo } \\
\text { merespon ketika } \\
\text { barang dideteksi } \\
\text { oleh sensor }\end{array}$ \\
\hline 7 & $\begin{array}{l}\text { Barang } \\
\text { Warna } \\
\text { Merah }\end{array}$ & Berhasil & $\begin{array}{l}\text { Motor servo tepat } \\
\text { mendorong Barang } \\
\text { setelah melewati } \\
\text { sensor (delay } 4 \\
\text { sekon) }\end{array}$ \\
\hline
\end{tabular}

\begin{tabular}{|c|c|c|c|}
\hline 8 & $\begin{array}{l}\text { Barang } \\
\text { Warna } \\
\text { Merah }\end{array}$ & Berhasil & $\begin{array}{l}\text { Motor servo tepat } \\
\text { mendorong Barang } \\
\text { setelah melewati } \\
\text { sensor (delay } 4 \\
\text { sekon) }\end{array}$ \\
\hline 9 & $\begin{array}{l}\text { Barang } \\
\text { warna lain }\end{array}$ & Error & $\begin{array}{l}\text { Motor Servo } 1 \\
\text { Merespon ketika } \\
\text { barang dideteksi } \\
\text { oleh sensor } \\
\text { sedangkan motor } \\
\text { servo 1 digunakan } \\
\text { sebagai motor } \\
\text { pendorong warna } \\
\text { hijau }\end{array}$ \\
\hline 10 & $\begin{array}{l}\text { Barang } \\
\text { warna lain }\end{array}$ & Error & $\begin{array}{l}\text { Motor Servo } 2 \\
\text { merespon ketika } \\
\text { barang dideteksi } \\
\text { oleh sensor } \\
\text { sedangkan motor } \\
\text { servo } 2 \text { digunakan } \\
\text { sebagai motor } \\
\text { pendorong warna } \\
\text { merah }\end{array}$ \\
\hline 11 & $\begin{array}{l}\text { Barang } \\
\text { warna } \\
\text { Lain }\end{array}$ & Berhasil & $\begin{array}{l}\text { Motor servo } 1 \text { dan } \\
\text { Motor Servo } 2 \text { tidak } \\
\text { merespon ketika } \\
\text { warna barang di } \\
\text { deteksi oleh sensor }\end{array}$ \\
\hline
\end{tabular}

Berdasarkan hasil pengujian dan pengukuran diatas maka didapat hasil seperti Tabel 6.Alat penyortir barang berdasarkan warna merah dan hijau ini dapat berjalan dengan baik tanpa ada error yakni relay memberi delay kepada conveyor supaya sensor TCS230 dapat mendeteksi warna hijau dengan baik dan motor servo 1 dapat mendorong barang berwarna hijau ke box dengan baik. Begitu juga sebaliknya ketika sensor TCS230 mendeteksi barang warna merah, relay memberi delay kepada conveyor selama 4 sekon supaya motor servo 2 dapat mendorong barang berwarna merah ke box dengan baik

\section{KESIMPULAN}

Berdasarkan perancangan sistem dan hasil analisa yang didapat maka dalam pembuatan prototype dapat disimpulkan beberapa hal, yaitu:

- Pada Alat penyortir barang berwarna merah dan hijau ini menggunakan PLC Schneider sebagai pengendali.

- Ketika Sensor mendeteksi barang berwarna Hijau PLC Schneider yang digunakan sebagai pengendali memerintahkan relay memberi delay selama 2 sekon untuk Motor Conveyor.

- Barang berwarna merah dan hijau sudah dapat dipisahkan dengan menggunakan sistem kendali berbasis PLC Schneider. 
- Terdapat keterbatasan didalam pengujian yang dilakukan, ketika beberapa kali dicoba alat tidak bisa mendeteksi barang yang masuk secara bersamaan dengan berbeda warna.

\section{SARAN}

Penyusun menyadari bahwa masih banyak yang dapat dikembangkan dari alat ini baik oleh penyusun sendiri. Maka dari itu penyusun memberikan saran yang dapat berguna untuk mengembangkan alat ini, diantaranya :

1) Dalam penyeleksian barang warna merah dan hijau perlu diatur lagi untuk pendeteksian warna hijau dan merah yang tidak pekat atau transparan.

2) Menggunakan Motor DC tipe yang lain supaya bergerak lebih akurat dan lebih efisien.

3) Supaya penyortiran dapat mencakup warna yang lebih banyak, sensor warna TCS230 dapat diganti dengan sensor warna lain yang dapat mendeteksi warna lebih banyak dari sensor warna TCS230 dan jumlah barang yang dideteksi oleh sensor tersebut.

\section{DAFTAR PUSTAKA}

1. Dwi,Friza, 2017,Sistem Kontrol Alat Sortir Objek Berwarna Merah dan Hijau Berbasis Arduino Due. Tugas Akhir D3 Teknik Elektro (tidak diterbitkan), Universitas Diponegoro, Semarang.

2. Aulia, Yudha Pohan, 2012, Rancang Bangun Miniature Conveyor Pemisah Barang Berdasarkan Ukuran Dimensi Kotak Box Berbasis Arduino Mega 2560. Tugas Akhir D3 Teknik Elektro (tidak diterbitkan), Universitas Diponegoro, Semarang.

3. Supegina, Fina, 2014,Perancangan Robot Pencapit Untuk Penyortir Barang Berdasar Warna LED RGB Dengan Display LCD Berbasis Arduino Uno. Tugas Akhir S1 Teknik Elektro (tidak diterbitkan), Universitas Mercu Buana, Jakarta.

4. Arbye, S , 2014, Pengendalian Pada Prototype Konveyor Pemisah Barang Berdasarkan Warna Menggunakan Sensor DT-Sense Color Dengan Controller Atmega 16 Dan PLC Omron CPM1-A, Tugas Akhir S1 Teknik Elektro (tidak diterbitkan), Universitas Diponegoro, Semarang.

5. Rahmatullah, Rizky, 2016, Rancang Bangun Sistem Sortir Produk Kemasan Berdasarkan Berat Berbasis PLC, Tugas Akhir D3 Otomasi Sistem Instrumentasi, Universitas Airlangga, Surabaya.

6. Qorib,Hadiyan Fathul, 2017, Rancang Bangun Sistem Kontrol Dispenser Otomatis Dengan Suhu Tertentu Menggunakan Aplikasi Android Berbasis Arduino, Tugas Akhir D3
Teknik Elektro (Tidak Diterbitkan), Universitas Diponegoro, Semarang. 